\title{
Assessing the Impact of Derived Behavior Information on Customer
}

\section{Attrition in the Financial Service Industry}

\begin{abstract}
The value of the customer has been widely recognised in terms of financial planning and efficient resource allocation including the financial service industry. Previous studies have shown that directly observable information can be used in order to make reasonable predictions of customer attrition probabilities. However, these studies do not take full account of customer behavior information. In this paper, we demonstrate that efficient use of information can add value to financial services industry and improve the prediction of customer attrition. To achieve this, we apply an orthogonal polynomial approximation analysis to derive unobservable information, which is then used as explanatory variables in a probit-hazard rate model. Our results show that derived information can help our understanding of customer attrition behavior and give better predictions. We conclude that both researchers and the financial service industry should use derived financial information in addition to directly observable information.
\end{abstract}

Key words

Customer attrition; Derived behavior information; Orthogonal polynomial approximation; Predition; Probit-hazard model. 


\section{Introduction}

Increased competition in the financial service industry has meant that the retention of existing customers has significantly become more important, especially due to the potential impact on revenues. Customer retention has also been increasingly of interest to academic researchers especially in areas of risk assessment and customer behavior, including customer attrition and attraction (Ganesh et al. 2000; Glady et al. 2008). Financial service firms that lose existing customers and have to seek new customers incur more expense than those that retain their customers, not to mention the associated risks involved in taking on new customers (Verbeke et al. 2012). Studies have shown that various sources of information can be used for monitoring financial customer behavior in order to facilitate customer-centric processes (Lessmann and Vob 2009). Dekimpe and Degraeve (1997) identify that customer demographics are associated with attrition behaviour. Athanassopoulos (2000) and Buckinx and Van den Poel (2005) provide evidence that product-specific features have significant impacts on customer attrition. In addition to studying the impact of customer demographic and product-specific features, Van den Poel and Lariviere (2004) also investigate customer attrition behaviour changes under different macroeconomic environment. Bose and Chen (2009) provide an excellent review on types of data used in quantitative models for customers' behaviour research.

Thomas (2010) draws attention to many of the challenges for research in customer behaviour finance, including a lack of focus and integration of marketing information on the behavior of financial customers. Chen et al (2012) further point out that customer behaviour is dynamic and the relation evolves overtime. As a result, an essential part of customer relation should be based on customer lifetime value. However, these studies generally attempt to use directly observable information to identify and explain customer attrition behavior. They do not consider the importance of derived information that can help the financial 
service industry understand and predict customers' attrition behavior in a variety of other ways. Blochlinger and Leippold (2006) show that informationally privileged financial services firms have competitive advantages over other financial firms.

Based on a classical orthogonal polynomial approximation approach, this paper derives indirectly observable information from a unique panel dataset, which records the value of the financial policy holdings history for each customer on a monthly basis. We simultaneously consider the customer attrition process and the customer relations established during the initial process of setting up the financial policy. This broader approach allows us to examine the relations between the two processes and accommodate unobservable heterogeneity. The derived information can provide financial firms with special insights for understanding customer attrition behavior. To our knowledge this paper is the first to examine whether derived information can be exploited by systematically analyzing customer financial behavior. It shifts the focus of the issue from one using directly observable information to one in which derived information can also provide valuable information for the estimation and prediction. This shift is in accord with the study of customer behavior, where behavioral factors affect the probability of customer attrition.

The results show that, in addition to directly observable information, the derived information can explain customer attrition behavior and detect triggers for attrition. Both of these sources of information form essential elements in understanding customer behavioral attrition with financial firms. The findings of this study further point to the benefits of incorporating derived information to improve the precision of customer attrition prediction. Specifically, the explanatory variables derivable from fluctuations in the value of the financial policy holding can contribute to the attrition probability prediction. One possible explanation for this is that after customers initially set up relations with a financial firm, their attrition behaviour is dynamic and subject to many ongoing factors, such as the external 
economic environment or various personal reasons. Personal reasons can motivate customers to change the value of their financial policy holdings. Such changes could provide useful information for financial firms to infer customers' attrition behavior. Financial service firms seeking to use relevant information more efficiently will therefore find the results interesting. The empirical results also suggest significant correlation between financial policy purchasing and attrition processes.

The rest of the paper is as follows. In Section 2 we discuss the research questions. Section 3 presents the data description and the variables used to estimate the model. This section demonstrates the method of deriving certain factors used as explanatory variables in the model. Section 4 outlines the specification and estimation of the probit-continuous hazard multi-process model. Section 5 presents the empirical results and a discussion of these findings. Section 6 provides the overall model fit tests and the comparison of predictive power of the models with and without the derived information. Section 7 presents concluding remarks and the implications of the findings.

\section{Research questions}

The general question to be addressed in this study is to investigate the relation between various factors and customer attrition and, in particular, whether or not derived information can explain customer attrition behaviour. Our first set of hypotheses are based on Van den Poel and Lariviere (2004) who suggest customer demographics can have impacts on customer attrition. For example the empirical evidence on whether or not there is a difference between male and female customers attrition behaviour is mixed. Both Mittal and Kamakura (2001) and Van den Poel and Lariviere (2004) suggest male customers tend to have higher attrition rate than female customers. On the other hand Dekimpe and Degraere (1997) find women are more likely to quit than men. Other research tends to suggest that 
older (married) customers are less likely to leave the firm than younger (unmarried) ones.. Finally, Mittal and Kakura (2001) and Van den Poel and Lariviere (2004) examine whether social status and country of origin have an impact on customer attrition. The results are mixed.

Based on this previous empirical evidence we formalize our investigation of the impact of customer demographics on attrition in the following hypotheses:

Hypothesis 1a: There is a positive relation between male customer and attrition behaviour.

Hypothesis 1b: There is a negative relation between customer age and attrition behaviour.

Hypothesis 1c: There is a negative relation between the customer marital status and attrition behaviour.

Hypothesis 1d: There is a relation between customer financial status and attrition behaviour.

Hypothesis 1e: There is a relation between customer country origin and attrition behaviour.

Our second hypothesis also follow those proposed by Van den Poel and Lariviere (2004) as we consider the impact of macroeconomic conditions, including UK stock market performance, house market performance, interest rate, and customer confidence on customer attrition. Prior research has shown that the conditions of external economic environment can have strong and statistically significant effects on customer financial decisions. Van den Poel and Lariviere (2004) point out that customers experience more switching tendencies in a favorable macro-economic environment. Thomas et al. (2005) find that customers are more likely to purchase financial policy products with the rise of stock market and housing market. Tang et al. (2007) further show that external economic environment can significantly impact customers' subsequent financial policy product purchase behaviours. Following this evidence we expect that the macroeconomic variables can influence the aspect of customer attrition behaviour. 
Hypothesis 2: There is a relation between customer attrition behaviour with macroeconomic conditions.

Our third hypothesis is our main contribution to the literature as it investigates the effects of derived information about customer financial policy values on customers' attrition behaviour. Derived information is created though the approach of orthogonal polynomial approximation (see section 3.2 for details). Though the impact of derived information has rarely been investigated in previous customer attrition literature, we feel that such derived information can be related to customer perception variables. Van den Poel and Lariviere (2004) provide an excellent review on the impact of customer perception predictors on attrition such as company versus competitors performance, customer overall satisfaction (Keaveney 1995; Bolton et al. 2000) and service quality (Athanassopoulos, 2000). These empirical studies find a significant decline in customer attrition for firms with better performance and service quality. Thus we expect that financial firms delivering higher values for financial policies will tend to reduce the likelihood of customer attrition.

Hypothesis 3: There is a relation between customer attrition behaviour with derived information based on the value of financial policies.

\section{Data and specification of derived variables}

\subsection{Data description}

This section describes the data and the relevant social-demographic and macroeconomic variables used in our study.. Collection of the data need for this type of study is difficult and this study was only possible as a major financial insurance company in Great Britain provided the data, as long as it remained anonymous. The data consists of 19,774 customers who purchase 20,257 financial policies over the 36 months period, from April 2001 through March 2004 (an average of 1.02 financial policies with a standard derivation of 0.17). Of the 19,774 customers, the vast majority $(19,321)$ customers hold single policies. 
The rest hold multiple policies and the highest number of policies is 5. Customers register with the firm at various times, i.e., not all customers have all 36 months of records available. For each customer, the data record provides observable information on the socialdemographic background: gender, age, marital status, financial status, region, type of financial policy, and payment frequency. All of the policies provide the policy start date and the policy end date. Profiles of the 19,774 customers in the data set are as follows: $54.3 \%$ are male; $6.9 \%$ customers are under 20 , the $20-35$ years old customer account for $18.8 \%, 36 \%$ customers are in the 35-to-55 age group, the rest are those customers aged over 55 and the mean age of the customers is $48 ; 15.1 \%$ are married; $37.5 \%$ have high financial status (financial A category), 37.6\% have intermediate financial status (financial B category), and the rest have low financial status (financial $\mathrm{C}$ or beyond category); $74.2 \%$ of the customers live in England, $17.9 \%$ live in Scotland, and the rest live in Ireland. Customers can purchase three kinds of financial policy. The first policy group consists of collective investment policies, such as unit trusts (i.e., mutual funds) and individual saving accounts (ISAs). The second group consists of life insurance policies and the final group consists of pension policies, such as personal pensions and stakeholder pensions.

\section{Table 1 here}

Table 1 shows the number of policy changes over the 36 months period. Of all 20,257 purchased policies, $16,578(82 \%)$ consists of collective investment policies and the rest are life insurance and protection policies. This study differentiates two main groups: an investment policy group and a non-investment policy group. One would expect a difference between investment and non-investment products as investment products the returns are directly linked to the value of the assets, thus carrying risks. Customers can withdraw the cash value of the units, subject to possible surrender charges. Early termination of the policy may be costly and the cash value payable may be less than the total premiums paid. Non- 
investment products like insurance are often renewed on an annual basis and so there are regular opportunities for the customer to churn to another company. The returns from noninvestment products will not necessarily track the ups and downs of investment markets. A part of the cash values under a participating non-investment policy will be guaranteed Within the three years customers terminate (churn) a total of 10,050 policies, and continue with10,207 policies. Over $90 \%(9,180 / 10,050)$ of the churned policies consist of investment related policies. These figures show that large numbers of customers fail to continue with their investment policies. Since all customers in the sample set up the relation with the financial insurance company after April 2001 and we know what the start date for each customer is, we do not need to deal with the issue of left censoring where the attrition event occurred before April 2001.

Figure 1 here

Figure 1 displays the empirical product-limit estimator (also known as Kaplan-Meier estimator) for estimating survival function describing survival distributions curve in our sample. The horizontal axis shows the duration time and vertical axis gives the survival probabilities for each time period. The Kaplan-Meier estimate probability shows that a customer will survive with the insurance company for 5 months or more is 0.909 . It declines to 0.705 and 0.602 for 20 months and 30 months or more, respectively. The median duration for the policies that continue with the insurance company is 34 months (median is the preferred measure of central tendency for censored survival data). There are 10,112 customers with 10,201 policies still remaining with the firm (i.e. right censored) at the end of data period. Accordingly, 9,739 customers terminate 10,050 policies during the three-year sample period.

The data provided by the UK financial insurance company also records the value (in UK sterling) of financial policy holding changes for every customer each month, depending 
on the duration of the customer's policy. The value of financial policy holdings used in the analysis represents the true movements in customer holdings as the effects of the stock market have been stripped out. In doing so, the value of policy holdings reflects the true customers' attrition to the financial insurance firm. The records consist of a sequence of times and holding values $\left\{(t(1), u(1)), \ldots,\left(t\left(n_{k}\right), u\left(n_{k}\right)\right)\right\}$ for customer $k$. The length of the sequence $n_{k}$ varies from customer to customer, depending on the duration with the firm. The value of holdings is a function of time, piecewise constant with jumps where the holdings change. In line with Thomas et al. (2005) and Tang et al. (2007), the analysis also includes four external macroeconomic variables, since attrition decisions made by customers can be influenced by exogenous economic environmental conditions. Here the chosen variables reflect the attractiveness of the general economic climate. The external UK economic variables are the Customer Confidence Index, the House Price Index, the FTSE All Share Index, and the Bank of England Base Interest Rate. The Augmented Dickey-Fuller unit root test shows that these economic variables except for Customer Confidence Index are nonstationary. Therefore those non-stationary variables are transformed by taking the first difference of the natural logarithm. Table 2 presents all of the variables used in the analysis.

\section{Table 2 here}

\subsection{Derived variables through orthogonal polynomial approximations}

The entire dataset contains detailed information of the financial policy holding value movements for each month for each customer. To derive information from the monthly financial policy holding values requires a consistent parameterization of the holding curve for each customer. Since the policy holding curve reflects the value of holdings held by the customer over the entire period of the data, this will indicate whether and when the customer left the firm. Therefore, this analysis does not use the full time series of the customer's 
holding values to derive further information and then predict when the customer owns zero values, but only uses the holding values from period 1 to $n_{k}-1$ for customer $\mathrm{k}$.

This paper uses an orthogonal polynomial approximation of order 3, in which each order component, $\mathrm{z}_{i}$, measures the level final holding value, the linear trend, the quadratic curvature, and change in curvature, i.e. cubic component, respectively. The orthogonal polynomial approximation makes the size of each component (level, linear, quadratic and cubic) invariant of the others, which guarantee the variance estimates would not be influenced by each other. Wetherill (1981) provides details of their construction. Orthogonal polynomial approximation has previously been used by Johnson et al. (2006), where they apply orthogonal polynomial approximation approach to derive predictors from speculative market price movement and then test whether the market effectively account for information contained in market prices. The Appendix provides details of calculating parameters for each component through orthogonal polynomial approximation.

The holding value can be interpreted differently when the holding values are decreasing or increasing. For example, if a customer pays in a regular contribution or reinvests the income into a policy, the value of the holdings increases irrespective of the movements in the market. Customers can also take a certain amount of money out of the policy to use as income. If this exceeds the amount by which the policy grows, then the value of holdings will decrease. This suggests a different interpretation for downward holding changes. Accordingly, all components except the level component split into two parts, $\mathrm{z}_{i}^{+}$and $\mathrm{z}_{i}^{-}$, depending on whether the value of the holdings moves up or down. That is, $\mathrm{z}_{i}^{+}=\mathrm{z}_{i}$ if $\mathrm{z}_{i}>$ 0 , otherwise 0 , and $\mathrm{z}_{i}^{-}=\mathrm{z}_{i}$ if $\mathrm{z}_{i}<0$, otherwise 0 .

\section{The statistical model of attrition}


This section presents the statistical model for joint estimating the policy purchasing and attrition processes. In order to simultaneously estimate the financial policy purchasing and customer attrition processes, this paper applies the following joint probit model (Equation (1)) and continuous hazard model (Equation (2)) to govern the two processes respectively. That is

$$
\begin{gathered}
d_{j}{ }^{*}=\alpha_{0}+\alpha_{1}^{\prime} X+\alpha_{2}^{\prime} Y_{t}+\varepsilon \\
\text { with } \mathrm{d}_{\mathrm{j}}=1 \text { if } \mathrm{d}_{\mathrm{j}}{ }^{*}>0 \text { and } \mathrm{d}_{\mathrm{j}}=0 \text { if } \mathrm{d}_{\mathrm{j}}{ }^{*} \leq 0 \\
\log h_{j}\left(t, X_{j}, Y(t), Z_{j}\right)=\beta_{0}+\beta_{1}^{\prime} T(t)+\beta_{2}^{\prime} X+\beta_{3}^{\prime} Y(t)+\beta_{4}^{\prime} Z+\beta_{5} d_{j}+\delta
\end{gathered}
$$

where variable $d_{j}$ is a dummy variable that is set to 1 if the $j^{\text {th }}$ investment related policy is purchased; $d_{j}^{*}$ is the unobservable utility as perceived only by the customer. $\log h_{j}(t, X, Y, Z)$ is the conditional log-hazard of attrition at time $\mathrm{t}$, representing the time duration since the start of the policy. $T(t)$ in equation (2) designates the base-line log-hazard pattern which is approximated by the piecewise-linear Gompertz with three nodes in this study. $X$ denotes the set of social-demographic measures of the customer. $Y(t)$ in equation (2) represents time-varying economic variables whose values change at discrete times in spell and constant over the span between those changes. $Y_{t}$ in equation (1) is the economic variable value vector when a customer purchases a financial policy product. The orthogonal polynomial approximation vector for derived information is given by $Z$. Control variables $X$, $Y(t)$, and $\mathrm{Z}$ represent three different information contents which are to be investigated for customer attrition process. The random residuals $\varepsilon$ and $\delta$, capturing the unobservable heterogeneity, are assumed to have a bi-variate normal distribution with zero mean and variance-covariance matrix to be estimated as

$$
\left(\begin{array}{l}
\varepsilon \\
\delta
\end{array}\right) \sim N\left(\left(\begin{array}{l}
0 \\
0
\end{array}\right),\left(\begin{array}{cc}
\sigma_{\varepsilon}^{2} & \rho \sigma_{\varepsilon} \sigma_{\delta} \\
& \sigma_{\delta}^{2}
\end{array}\right)\right)
$$


where $\rho$ is the correlation coefficient between the unobservable heterogeneity terms of the two processes. The hazard rate of attrition, given by equation (2), is a function of socialdemographic variables $X$, time-varying macro-economic variables $Y$, and derived variables $Z$. Thus, each group of variables provides insights about the directly observable 'static', 'dynamic' and unobservable derived information, respectively. In addition, including component $d$ in equation (2), allows us to analyze the impact of the kind of purchased policy on the risk of attrition.

After estimating relevant parameters, we can calculate the predicted survival probability for each customer in the holdout sample. The analysis applies the Nelson-Aalen estimate of the baseline cumulative hazard function. Collett ((2003), p.257-258, eq.8.3 and eq.8.5) provides details of the calculations. Considering there are $n$ customers, among whom there are $r$ distinct attrition times and $n-r$ right-censored survival times. Then the base cumulative hazard function for $H_{0}(t)$ is obtained as

$$
H_{0}(t)=-\log S_{0}(t)=\sum_{j=1}^{J} \frac{e_{j}}{\sum_{l \in R\left(t_{j}\right)} \exp \left(\hat{\beta} x_{l}(t)\right)}
$$

for $t_{J} \leq t<t_{J+1}, J=1,2, \cdots, r-1$, where $S_{0}(t)$ is the baseline survivor function, $R\left(t_{j}\right)$ is the group of customers who are still with the company at a time just prior to $t_{j}, x_{l}(t)$ is the vector of explanatory variables for the $l^{t h}$ customer at time $t$, and $e_{j}$ is the number of events at the $j^{\text {th }}$ ordered event time, $j=1,2, \cdots, r$. With this in hand, we obtain the approximate conditional probability of surviving through the interval $(t, t+h)$ for customer $i$ in the sample (Here we let $h=1$ )

$$
\tilde{P}_{i}(t, t+h)=\exp \left[-\left\{H_{0}(t+h)-H_{0}(t)\right\} \exp \left(\hat{\beta} x_{i}(t)\right)\right]
$$




\section{Estimation results}

Approximately 70 percent from the whole dataset, drawn randomly, forms the training sample for model estimation. The remainder forms the holdout validation set used to further refine and examine the accuracy of the model. The training dataset provides the data for estimating the model while the holdout dataset provides the data for comparing the predicting performance with and without the derived information. Table 3 presents the joint maximum likelihood estimates for the joint probit- hazard multi-process models with and without derived information using $a M L$ (Lillard and Panis, 2003). In Table 3, Panel I reports the coefficient estimates for the policy purchasing and customer attrition processes. Panel II presents the results for heterogeneity and correlation coefficient components.

\section{Table 3 here}

The coefficients for the baseline log-hazard are all statistically significant in all periods. The attrition risk of the first 12 months rises (slope $1=.08$ ), it continues to rise further and more sharply (slope $2=.11$ ) reaching a maximum at about $18^{\text {th }}$ month. Then the attrition rate decreases until the $24^{\text {th }}$ month (slope $3=-.13$ ). However after two years, the attrition rate again rises sharply (slope $4=.23$ ). The estimation results indicate that the probability of purchasing investment policies and the risk of attrition are affected by socialdemographic variables. The dummy variable for gender, male, is significantly positive for customer duration processes (.14). This suggests that male customers have a $15 \%(\exp (.14)$ 1) higher attrition rate than female customers. Not surprisingly, married customers seem more risk averse than unmarried customers. Married customers are far less likely to invest in risky investment policies, probably due to having children. They tend to keep a longer relation with the financial insurance firm. The impacts of other social-demographic variables on each process are slightly different. Dummy variables for age, financial status, and region 
categories are used as indicators of customer social backgrounds. The customer's age plays a significant role in the rate of attrition. Those aged between 35 and 55 have the lowest attrition rate compared with other age brackets. Customers in the highest financial bracket (financial A) have an attrition risk that is $17 \%$ less than the reference, financial B customers. The attrition hazard risk of customers with low financial status (financial $\mathrm{C}$ or beyond) rises to 19.2\% above that of financial status B customers. Another interesting finding is that the rate of attrition seems to be the same for all customers no matter which geographical area they come from within the UK. The attrition rate for monthly payment customers rises by nearly $169 \%$ compared with other frequency payment customers when other things are equal. The empirical results are consistent with previous literature, providing some support for the first set of hypotheses in that customer demographics are related to attrition behaviour. The set of coefficients that measure the effect of economic conditions are all significantly different from zero except for the customer confidence index variable. This suggests that perceptions of the national economy are related to the hazard rate of customer attrition. The coefficient that captures the influence of the stock market is consistently negative with values around -2.32 , implying that, on average, customers' attrition risk declines by 90 percent when the stock market goes up. This is not a surprising result in that the value of financial policies tends to increase with a rising stock market. The housing market does not have such a dramatic impact as the stock market. However, the estimated coefficient (-.01 with a t-value of -3.34$)$ still implies the risk of attrition declines significantly with the rising of the housing market. The interest rate has higher impact on attrition than house price. Overall, the results support Hypothesis 2 that external macroeconomic environment influence financial customers' attrition behaviour. When comparing the magnitudes and significance of relevant estimated coefficients, there are almost no differences between the models with and without the derived 
information except for the variable of "policy". The effect of this variable becomes insignificant when adding derived information. This might be due to the fact that ???

The estimated correlation coefficient $\hat{\rho}$ measures the association between the policy purchase decision and the hazard rate of attrition. The result with respect to the significance of $\hat{\rho}$ shows the presence of statistically significant systematic factors driving the two processes (equal to .29 and .36 for without and with derived information, respectively). The non-zero correlation between heterogeneity components of $\varepsilon$ and $\delta$ indicates that customers with a higher probability of purchasing investment policies also tend to have higher risks of attrition. A key advantage, therefore, of the joint estimation approach is that it can control the potential problem of endogeneity such as that noted by Boyes and Low (1989). Another advantage is that it can easily accommodate the unobservable heterogeneity that affects both policy purchase and attrition processes. The significance of heterogeneity component for the hazard rate function $\sigma_{\delta}^{2}$ (equal to 1.65 and 1.63 for with and without derived information) suggests that there is substantial unobservable heterogeneity in the risk of attrition after allowing for both observable and derived covariates. Since the estimates are consistent both with derived information and without derived information, the following discussion limits itself to the effects of the variables in the model with derived information.

The main objective in deriving information from the value of financial policy holdings is to evaluate customers' attrition to the firm. Some customers re-invest the income generated from the policies each month. The value of these policies will therefore change month on month. This could be a reflection of customers slightly increasing their attrition behaviour to the firm. On the other hand, if the value of policy holdings changes quite considerably, this is likely to be as a result of customers increasing/decreasing their premiums (when customers stop paying premiums, their policy holdings will drop to zero and the 
relation with the firm is terminated). Studying the movement of policy holdings and identifying what is income re-investment and what is increased/decreased premium provides valuable insights for understanding and predicting customers' attrition behavior.

Indicators of information derived from the value of policy holding values form the parameters of the four main orthogonal components: absolute level, that is the latest financial policy holding (there could be various ways of representing this component, such as the average or weighted average of holdings over the time of duration); linear holding, that is holding trend; quadratic holding, that is the holding curvature, and cubic holding, that is the change of holding curvature. The significant impacts of some components of risk attrition demonstrate that it is important to account for this derived information. The increasing order of orthogonal components in terms of statistical significance appears to mitigate the effects of derived information (this explains why an orthogonal polynomial approximation of order 3 is applied).

The absolute level effect on the risk of attrition is significantly negative at any reasonable level (-.65 with a t-value of being -3.5). This implies that the higher the customer's absolute value of policy holdings, the less likely he or she is to terminate the relation with the firm. A higher value of policy holdings means that the customer puts more money into the policy he or she purchased. This usually suggests that the customer expects that the return for the customer will rise with the rise in value of the policy held. Thus the risk of terminating the relation with the firm declines.

The linear effect of holdings is divided into two parts: linear trend up and linear trend down (see definitions at the end of section 3). The coefficient for the increasing linear component is significantly negative at $1 \%$ level $(-1.87$ with a t-value of -18.1$)$. This indicates an inverse relation exists between the risk of attrition and the increase in value of policy holdings. The reason why policy holdings increase linearly is that the customer puts money 
into the policy regularly and purchases a set amount of holdings, suggesting that the customer commits more to the firm as the holdings increase. As a result, the customer's holdings increase irrespective of the movements in the market. It should be noted that the value here refers to real holdings that exclude the market effects of fluctuating fund values.

Surprisingly, decreasing holdings also reduce the risk of attrition (-.43 with a t-value of -5.20). The most likely reason for decreasing policy holdings is that the customer takes out a regular fixed income from the policy. For example, a customer could take fixed funds out of the investment each month (e.g. £500) to use as a regular income. As a result, although the value of holdings declines at a constant rate, this is not an indication of decreasing customer commitment to the firm.

Policy holders can decide the rate at which they increase or decrease the premiums of their policy holdings. By calculating higher order orthogonal components, the analysis captures dramatic increases and decreases in premiums. The nonlinear quadratic down component is significantly positive at $5 \%$ level (12.95 with a t-value of 2.28$)$ while the quadratic up and cubic down components are statically insignificant but have expected signs. This suggests that if a customer takes out income from the policy at a rate which exceeds the rate at which the policy is growing or reduces premiums dramatically, the risk of attrition increases significantly such that the customer will soon terminate the relation with the firm. The cubic up component is also statistically significant (-4.64 with a t-value of -2.52$)$, suggesting the risk of attrition declines as the value of the holdings rises at a higher accelerated rate. To what extent the additional derived information variables to reduce the unexpected variation in the dependent variable can be measured by McFadden pseudo $R^{2}$. Menard (2000) suggests that McFadden pseudo $R^{2}$ satisfy all of Kvalseth (1985)'s eight criteria for a good $R^{2}$. The McFadden pseudo $R^{2}$ results show that the value of $R^{2}$ with derived information increases from 0.114 to 0.122 when derived information variables are included. 
One reason for the relatively low $R^{2}$ values is that we are dealing with individual customers who reveal limited information. A significant improvement on $R^{2}$ would require an abundance of personal information. Nevertheless, these empirical results clearly show that different orders of components derived from orthogonal polynomial approximation show different customer attrition behavior patterns, therefore providing support the third hypothesis.

Although research techniques in the behavioural finance literature are increasing in efficiency and sophistication, there is still room for further improvement, not only in terms of model fitting but also in terms of the efficient use of information. In particular, the information conveyed by non-directly observable information can add explanatory power for estimating risk attrition. The results of the explanatory variables highlight the potential benefits of using derived information. The derived information would predict attrition several months prior to a customer's departure through identifying within the customer's account if, for example, deductions begin to fall off and assets begin to decrease dramatically. The results can also have substantial practical value, as they change our views on how to obtain relevant information signals in order to better understand customer attrition behavior. A financial service firm can assess and monitor the behavior of its customers more accurately in future through gathering such signals such as how customers change the value of their policies. Financial service firms that invest in acquiring non-observable information can apply and design more effective marketing strategies, such as cross-selling a particular financial policy which satisfies customers' special needs, in order to retain customers. Above all, better screening and monitoring of customers can provide a firm with a competitive financial advantage over its rivals. 


\section{Comparison of predictive performance}

To assess the overall model fit, the analysis conducts in-sample tests comparing the model with derived information to the nested model without derived information by applying log-likelihood ratio test. A log-likelihood ratio test shows that the model incorporating derived components outperforms the model with only demographic and economic covariates. This suggests that the derived information plays an important role in explaining the probability of customer attritions $(\mathrm{LL}=-36347.78$ with derived information and $\mathrm{LL}=$ 36687.00 without derived information, $\chi^{2}=678$, degree of freedom $=7, p<.01$ ).

Making predictions is one of the fundamental objectives for financial service industry (Neslin et al. 2006). To further validate the results, this section assesses the importance of incorporating this information by comparing the predictive power of the models with and without the derived information. First, the analysis includes calculating predicted survival probabilities for each customer in the holdout sample using the estimated coefficients for the models with derived components and the model without derived information from Table 2. In the analysis this study uses all but the last observation for each customer to calculate predicted survival probabilities for next month.

Finally the analysis ranks customers in ascending predicted survival probabilities. Customers with lower predicted survival probabilities are more likely to terminate the relation with the firm for the specified time period. The model without derived information in general correctly predicts $62.47 \%(2,206$ out of 3,531$)$ terminating customers. The model with derived information correctly predicts $64.37 \%$ (2,273 out of 3,531$)$ terminating customers, suggesting it has a $1.90 \%$ better prediction rate than the model without derived information. This difference is economically significant for financial institutions considering the potential number of customers, which not only lead to a substantial increase in profits but also provide competition advantage for those institutions that retain customers better. The 
cut-off for classifying terminating and continuing customers is the ex-post proportion of attrition in the holdout sample $(3,531 / 7,498=.47$ the hazard rate $)$. The hazard rate model with derived information predicts only marginally better than the one without derived information. However, an accurate assessment of the probability of attrition in retail sale can give a financial firm a considerable competitive advantage over other firms. Even a small improvement of predicting the probability of attrition could bring financial service firms substantial increases in profits (Blochlinger and Leippold, 2006).

The forecasting power of derived information in distinguishing between low and high attrition risk customers can also be estimated by using the Receiver-Operator Characteristic (ROC) analysis. The ROC curve is a plot of true positive rate, $t p$, (i.e., the number of known survivors classified as survivors over total number of known true survivors) on the $\mathrm{x}$-axis versus false positive rate, $f p$, (i.e., the number of known attritions classified as survivors over total number of true attritions) on the y-axis for all possible values of decision thresholds. We first sort the predicted survival probability for each customer in the holdout sample in ascending order. The actual dummy attrition indicator (i.e., survivor $=1$; attrition $=0$ ) is then sorted accordingly for each customer. The ROC curve is independent from the decision thresholds and the further the curve away from the 45-degree diagonal, the higher the predictive power.

In order to examine the consistency of the model's performance, we further conduct nonparametric bootstrap simulation to explore whether the higher predictive power using derived information arises by fortunate selection of the training and validation data sets. Efron (1981) introduces an algorithm in which the non-parametric bootstrap analysis is used for censored data. The non-parametric bootstrap is a simulation where we resample with replacement from the original sample. Specifically, the bootstrap simulation procedure is conducted as follows: 
i. Based on the original data provided by the insurance company, we sample with replacement form the original data to get a new bootstrap sample. Thus, some customers will be selected more than once in this new sample or perhaps not at all.

ii. We then randomly split of the new bootstrap sample into new training and new validation data.

iii. The new training sample is then used to estimate the hazard model for both models with derived components and the model without derived information. With the relevant estimated coefficients we calculate bootstrap predicted survival probabilities for each customer in the new validation data. Using the bootstrap replicates of predictive survival probabilities, we then calculate the area under the ROC curves (AUC), which is a commonly used summary measure of predicting effectiveness. The value for the area under the ROC curve closing to 1 indicating perfect predicting effectiveness and 0.5 indicating the same accuracy as random guess.

iv. Replicating steps i through iv 1000 times.

Figure 2 here

Figure 2 presents the ROC curves for models with and without adding derived information in the holdout sample. In general, the model with the seven derived variables performs marginally better than the model without the derived information. However, it should be noted that there are three crosses for the ROC curves at three different decision thresholds especially for the second crossing point. This indicates that the model with the derived information is not uniformly better than the model without the derived information. Both the overall model fit test and the forecasting analysis reliably show the marginal improvement of the use of derived information in predicting customer attrition probabilities. We obtain that the average AUC value for hazard model with derived information is 0.6919 and without derived information is 0.6671 . This supports the analysis above that the better 
prediction of using derived information does not arise by 'fortunate' selection of the training and validation sets. Our results confirm Johnson et al. (2006) that derived variables through orthogonal polynomial approximations can produce better predicting probabilities. Though in a different setting, both this study and Johnson et al. (2006)'s study confirm that people are more effectively in discounting directly observable information than less directly observable information. Overall, the results of the bootstrap simulation analysis provide further evidence that the additional derived information can be exploited for financial service industry to better understand customer attrition behavior.

It has been proposed that simpler logistic or probit model can achieve similar predictive performance to complex models such as hazard model (Lee and Urrutia 1996). This leads us to a further demonstrate the added value of derived information on simple logistic model (Occam's razor). We conduct the bootstrap simulation from step $i$ to $i v$ except that the third step is for logistic model rather than for hazard model. However, it should be noted that time-dependent macro-economic variables cannot be estimated for logistic model while hazard model can handle time-dependent variables easily which is an advantage of over logistic model. Another advantage of hazard model is that it can take into account of censoring variables. The ROC curve for logistic model with and without derived information is presented in Figure 3.

Figure 3 here

The average SUC value for logistic model with derived information is 0.6920 and that of without derived information is 0.6456 , suggesting better predictive performance of derived information.

\section{Conclusion}


The value of customer has been widely recognised in terms of financial planning and efficient resource allocation. Customers are increasingly mobile and ever-more demanding. Understanding customer attrition behaviour has been the subject of considerable prior research; most research focus on using directly observable and commonly used information such as geographic, demographic and macroeconomic variables. This paper has demonstrated the value of derived information. The results of the study have implications for researchers in two broad areas. First, they provide evidence of the need to take customers' financial behaviour into account when attempting to investigate and predict customer attrition. While demographic and external economic environment can certainly affect customer attrition behaviour, it seems that in mature markets such as the one we examined, customer attrition behaviour is also driven by the customer's own experiences of the value of financial products.

The second area of implication for researchers relates to the study's contribution to the introduction of a statistical approach for deriving certain behavioral factors which measure customers' attrition behaviour to financial firms. This approach expands traditional views on the use of information in customer attrition and could be applied to areas of finance in which efficient use of information is involved, such as the subject of behavioral finance. In that context, the statistical techniques applied in this paper have been seen to be useful, and their application to the study of the behavior of financial customers and the subsequent effect on financial markets will be rewarding.

The findings of the study also have implications for financial services industry which is competing intensely for opportunities for financial product sales and customer loyalty. In addition to capturing customers' financial behavior changes, our findings clearly show that derived information can achieve nominally small but managerially meaningful increases in predictive accuracy. This suggests that customer behavior is a good source of information 
about their priorities, needs, and experiences. Therefore, financial firms should manage customer experience and collect more relevant information on the financial behaviour of customers for analysis if they desire to have a competitive advantage over other financial firms and increase the value of customers. Customer attrition can have a significant impact on profitability for financial firms. If derived information indicates that a customer might leave, financial firms are able to implement meaningful retention strategies and extend customers' lifespan by creating or offering new financial products with a focus on customer experience, flexibility, and appropriate pricing.

The limitations of the study in respect of the relatively small sample and the focus on only one financial firm suggest that the findings here needed to be primarily seen as exploratory. Further research is suggested that using data from other financial firms can generalize and strengthen our knowledge of derived information on customer attrition. Another area of interest concerns the contagion of customers' attrition decision. Analysis of this issue is beyond the scope of this paper, but this is an area for further research that would have clear managerial implications. The financial policy product market examined in this study is a mature market. Customers do not leave the market altogether but simply follow others to switch to competitors. Therefore, it might be worthwhile to collect this type of behaviour information. 


\section{Appendix}

Based on the observed monthly financial policy holding values $\left\{(t(1), u(1)) ; \ldots ;\left(t\left(n_{k}-1\right), u\left(n_{k}-1\right)\right)\right\}$ for customer $\mathrm{k}$, a sequence of orthogonal polynomials $f_{0}, f_{1}, f_{2}$, ... exists and satisfies

$$
\sum_{l=1}^{n_{k}-1} f_{i}(t(l)) f_{j}(t(l))=0 \text { for all } i \neq j
$$

There is a unique set of coefficients $a_{0}, a_{1}, a_{2}$, and $a_{3}$ following

$$
u(l)=\sum_{i=0}^{3} a_{i} f_{i}(t(l)) \text { for all } l=1, \ldots, n_{k}-1
$$

$a_{i}$ can be found by least squares. As the $f_{i}$ are orthogonal, $a_{i}$ signifies the size of the order $i$ component in the holding value. Because of the importance of the final holding value $u\left(n_{k}-1\right)$, let $f_{0}(t(n))=f_{0}(1)=1$ and $f_{i}(1)=0$ for all $i \geq 1$, we make the level component $\mathrm{a}_{0}$ equal to $u\left(\left(n_{k}-1\right)\right)$. This study also normalizes each $f_{i}$ so that its leading term is simply $t^{i}$. $a_{1}$ is the slope of the least squares regression line constrained to pass through $t\left(n_{k}-1\right), u\left(n_{k}-1\right)$. $a_{2}$ measures the holding curve curvature and $a_{3}$ measures the change in curvature. Thus, the values of $a_{1}, a_{2}$, and $a_{3}$ can be used to gauge customers' attrition to the financial firm. We illustrate the unit holding values, linear trend, quadratic and cubic approximations for a randomly chosen customer in Figure 4. Note we scale the times so that $t(1)=0$ and $t\left(n_{k}-1\right)=1$

Figure 4 here

When the number of monthly holding values, $n$, is small for customer $\mathrm{k}, a_{2}$ and $a_{3}$ will change dramatically if a small change in one of the holding values. A roughness penalty can mitigate this. Let $F(t)=\sum_{i=0}^{3} a_{i} f_{i}(t)$, then choose the $a_{i}$ to minimize

$$
\sum_{l=1}^{n_{k}-1}(u(l)-F(t(l)))^{2}+\lambda G(F)
$$


where $G(F)$ is the roughness penalty and $\lambda$ is some constant of proportionality. Here let $G(F)$ equal to the area of $F$ above $u_{\max }=\max u(i)$ and below $u_{\min }=\min u(i)$. That is,

$$
G(F)=\int_{0}^{1} \max \left(F(t)-u_{\max }, 0\right) d t+\int_{0}^{1} \max \left(u_{\min }-F(t), 0\right) d t
$$

In addition, the approximation incorporates two refinements of the parameter set based on our understanding of how holdings behave in practice. Since high value holdings change by larger amounts than low values, the relative size is thus more important than the absolute size of any change. Consequently, before calculating parameters $a_{1}, a_{2}, a_{3}$, the holding curve $\left.\left\{(t(1), u(1)) ; \ldots ; t\left(n_{k}-1\right), u\left(n_{k}-1\right)\right)\right\}$ is rescaled by dividing $u(i)$ by $u\left(n_{k}-1\right)$ for $i=1, \cdots, n_{k}$. 


\section{References}

Athanassopoulos, A. (2000). Customer satisfaction cues to support market segmentation and explain switching behaviour. Journal of Business Research 47, 191-207.

Blochlinger, A. Leippold, M. (2006). Economic benefit of powerful credit scoring. Journal of Banking and Finance 30, 851-873.

Bolton, R. Kannan, P. Bramlett, M. (2000). Implications of loyalty program membership and service experiences for customer retention and value. Journal of the Academy of Marketing Science 28, 95-108.

Bose, I. Chen, X. (2009). Quantitative models for direct marketing: A review from systems perspective. European Journal of Operational Research 195, 1-16.

Boyes, W. Low, H. (1989). An Econometric analysis of the bank credit scoring problem. Journal of Econometrics 40, 3-14.

Buckinx, W. Van den Poel, D. (2005). Customer base analysis: partial defection of behaviourally loyal clients in a non-contacted FMCG retail setting. European Journal of Operational Research 164,252-268.

Chen, Z. Fan, Z. Sun, M. (2012) A hierarchical multiple kernel support vector machine for customer churn prediction using longitudinal behavioural data. European Journal of Operational Research 223, 461-472.

Collett, D. (2003). Modelling survival data in medical research. Chapman \& Hall.

Dekimpe, M. Degraeve, Z. (1997). The attrition of volunteers. European Journal of Operational Research 98, 37-51.

Efron, B. (1981). Censored data and the bootstrap. Journal of the American Statistical Association 76, 312-319.

Ganesh, J. Arnold, M. Reynolds, K. (2000). Understanding the customer base of service providers: An examination of the differences between switchers and stayers. Journal of Marketing 64, 65-87.

Glady, N. Baessens, B. Croux, C. (2009). Modelling churn using customer life time value. European Journal of Operational Research 197, 402-411.

Johnson, J. Jones, O. Tang, L. (2006). Exploring decision makers' use of price information in a speculative market. Management Science 52, 897-908.

Keaveney, S. (1995). Customer switching behavior in service industries: An exploratory study. Journal of Marketing 59,71.82.

Kvalseth, T. (1985). Cautionary note about $R^{2}$. The American Statistician 34, 274-285. 
Lee, S. Urrutia, J. (1996) Analysis and prediction of insolvency in the property liability insurance industry: A comparison of logit and hazard models, Journal of Risk and Insurance 63, 121-130.

Lessmann, S. Vob, S. (2009). A reference model for customer-centric data mining with support vector machines. European Journal of Operational Research 199, 520-530.

Lillard, L. Panis, C. (2003). aML multilevel multiprocess statistical software, Version 2.0, EconWare, Los Angeles, California.

Menard, S. (2000). Coefficients of determination for multiple logistic regression analysis. The American Statistician 54, 17-24.

Mittal. V. Kamakura, W. (2001). Satisfaction, repurchase intent, and repurchase behaviour: Investigating the moderating effect of customer characteristics. Journal of Marketing Research 38, 131-142.

Neslin, S. Gupta, S. Kamakura, W. Lu, J. Mason, C. (2006). Defection detection: Measuring and understanding the predictive accuracy of customer churn models. Journal of Marketing Research 43, 204-211.

Tang, L. Thomas, S., Thomas, L, Bozzetto, J. (2007). It's the economy stupid: Modelling financial product purchases. International Journal of Bank Marketing 25, 6-22.

Thomas, L. Thomas, S. Tang L. Gwilym, O. (2005). The impact of demographic and economic variables on financial policy purchasing timing decisions. Journal of Operation Research Society 56, 1051-1062

Thomas, L. (2010). Consumer finance: challenges for operational research. Journal of the Operational Research Society 61, 41-52.

Van den Poel, D. Lariviere, B. (2004). Customer attrition analysis for financial services using proportional hazard models. European Journal of Operational Research 157, 196-217. Wetherill, B. (1981). Intermediate Statistical Methods, Chapman and Hall, London. Verbeke, W., Dejaeger, K. Martens, D. Hur, J. Baesens, B. (2012). New insights into churn prediction in the telecommunication sector: A profit driven data mining approach. European Journal of Operational Research 218, 211-219. 
Table 1: Number of policy changes from April 2001 to March 2004

\begin{tabular}{cccc}
\hline & Apr01-Mar 02 & Apr 01-Mar 03 & Apr01-Mar 04 \\
& & & \\
\hline Of which: Investment & 15,255 & 16,560 & 16,578 \\
Non-investment & 3,015 & 3,664 & 3,679 \\
Of which: Investment & 2,412 & 6,171 & 10,050 \\
Non-investment & 176 & 5,603 & 9,180 \\
Total number of policies terminated & 2,588 & 568 & 870 \\
Of which: Investment & 12,843 & 14,053 & 10,207 \\
Non-investment & 2,839 & 10,957 & 7,395 \\
& & 3,096 & 2,812 \\
\hline
\end{tabular}


Table 2: Definitions of the three sources of explanatory variables.

This table lists three sources of explanatory variables. The first source is social demographic variables provided by the UK financial insurance company. The second source is external economic variables. The economic variables are obtained from Datastream. The third source of explanatory variables is derived variables through orthogonal polynomial approximations. There are 22 explanatory variables including 15 directly observed and 7 derived variables.

\begin{tabular}{|c|c|}
\hline Variables & Definitions \\
\hline (1). Social demographic & \\
\hline Male & $\begin{array}{l}\text { A dummy variable of customer's gender. } 1 \text { if the customer is male, } \\
\text { otherwise } 0 \text {. }\end{array}$ \\
\hline Mariage & $\begin{array}{l}\text { A dummy variable of customer's marriage. } 1 \text { if the customer is married, } \\
\text { otherwise } 0 \text {. }\end{array}$ \\
\hline Age between 20 and 35 & $\begin{array}{l}\text { A dummy variable of customer's age. } 1 \text { if age is between } 20 \text { and } 35 \text {, } \\
\text { otherwise } 0 \text {. }\end{array}$ \\
\hline Age between 35 and 55 & $\begin{array}{l}\text { A dummy variable of customer's age. } 1 \text { if age is between } 35 \text { and } 55 \text {, } \\
\text { otherwise } 0 .\end{array}$ \\
\hline Age above 55 & A dummy variable of customer's age. 1 if age is above 55 , otherwise 0. \\
\hline Financial status A & $\begin{array}{l}\text { A dummy variable of customer's financial status. } 1 \text { customer's financial } \\
\text { status is classified A, otherwise } 0 \text {. }\end{array}$ \\
\hline Financial status CD & $\begin{array}{l}\text { A dummy variable of customer's financial status. } 1 \text { customer's financial } \\
\text { status is classified CD , otherwise } 0 \text {. }\end{array}$ \\
\hline Scotland & $\begin{array}{l}\text { A dummy variable of customer's region. } 1 \text { if customer is from Scotland, } \\
\text { otherwise } 0 \text {. }\end{array}$ \\
\hline England & $\begin{array}{l}\text { A dummy variable of customer's region. } 1 \text { if customer is from England, } \\
\text { otherwise } 0 \text {. }\end{array}$ \\
\hline Monthly Payment & $\begin{array}{l}\text { A dummy variable of financial payment frequency. } 1 \text { if payment is monthly } \\
\text { and } 0 \text { if yearly. }\end{array}$ \\
\hline Policy & $\begin{array}{l}\text { A dummy variable of financial policy being purchased. } 1 \text { if investment } \\
\text { policy is purchased, otherwise } 0 \text {. }\end{array}$ \\
\hline (2). Economy & \\
\hline Stock Return & Logarithm of first difference of monthly FTSE All Shares index. \\
\hline House Price & First difference of monthly UK house price index. \\
\hline Interest Rate & Monthly Bank of England base interest rate. \\
\hline $\begin{array}{l}\text { Confidence Index } \\
\text { (3). Parameterized }\end{array}$ & Monthly of UK customer confidence index. \\
\hline Absolute Level & The height of the holding values, i.e. the latest holding s. \\
\hline Linear UP & The linear orthogonal component with the value of holdings increasing. \\
\hline Linear DW & The linear orthogonal component with the value of holdings decreasing. \\
\hline Quad UP & The curvature (quadratic component) with the value of holdings increasing. \\
\hline Quad DW & $\begin{array}{l}\text { The curvature (quadratic component) with the value of holdings } \\
\text { decreasing. }\end{array}$ \\
\hline Cubic UP & $\begin{array}{l}\text { The change of curvature (cubic component) with the value of holdings } \\
\text { increasing. }\end{array}$ \\
\hline Cubic DW & $\begin{array}{l}\text { The change of curvature (cubic component) with the value of holdings } \\
\text { decreasing. }\end{array}$ \\
\hline
\end{tabular}


Table 3: Estimation of the joint Probit-hazard model.

This table examines the effect of directly observable information on the choice of policy purchasing applying Probit model and derived information on the probability of attrition applying hazard rate regression. The coefficients are the joint maximum log-likelihood estimates for the joint probit-hazard models in order to simultaneously estimate the customer attrition process and the customer relations established during the initial process of setting up the financial policy. Panel I reports the coefficient estimates for the policy purchasing and customer attrition processes. Panel II reports the estimate results for heterogeneity and correlation coefficient components. The sample period is April 2001 to March 2004.

\begin{tabular}{|c|c|c|c|c|c|}
\hline \multirow[t]{2}{*}{ Variables } & \multicolumn{2}{|c|}{ Without derived information } & \multicolumn{3}{|c|}{ With derived information } \\
\hline & Variable & t-value & Variable & t-value & Hazard ratio \\
\hline \multicolumn{6}{|c|}{ Panel I: Financial policy purchase process (Probit) } \\
\hline Constant & $-4.95 * *$ & -7.34 & $-5.12 * *$ & -7.41 & --- \\
\hline Male & 0.10 & 1.26 & .09 & 1.19 & --- \\
\hline Mariage & $-3.01 * *$ & -9.99 & $-3.03 * *$ & -10.1 & --- \\
\hline Age between 20 and 35 & $-1.04 * *$ & -4.14 & $-1.07 * *$ & -4.02 & --- \\
\hline Age between 35 and 55 & $-1.30 * *$ & -5.02 & $-1.33 * *$ & -5.07 & --- \\
\hline Age above 55 & $-1.03 * *$ & -4.08 & $-1.05^{* *}$ & -4.14 & --- \\
\hline Financial Status A & -.03 & -.35 & -.03 & -.35 & --- \\
\hline Financial Status CD & .12 & 1.21 & .116 & 1.21 & --- \\
\hline Scotland & .008 & .05 & .03 & .09 & --- \\
\hline England & .11 & 1.06 & .1089 & 1.03 & --- \\
\hline Stock Return & $-11.98 * *$ & -8.69 & $-12.10 * *$ & -8.71 & --- \\
\hline House Price & $.156 * *$ & 8.39 & $.159 * *$ & 8.41 & --- \\
\hline Interest Rate & $1.47 * *$ & 8.83 & $1.51 * *$ & 8.86 & --- \\
\hline Confidence Index & $-.32 * *$ & -9.54 & $-.33 * *$ & -9.56 & --- \\
\hline \multicolumn{6}{|l|}{ Attrition process (Hazard) } \\
\hline Constant & $-4.83 * *$ & -14.8 & $-3.84 * *$ & -11.6 & .021 \\
\hline Male & $.11^{*}$ & 2.57 & $.14 * *$ & 3.19 & 1.15 \\
\hline Marriage & $-.32 * *$ & -4.18 & $-.34 * *$ & -4.56 & .712 \\
\hline Age between 20 and 35 & $-.45 * *$ & -4.58 & $-.45 * *$ & 4.61 & .637 \\
\hline Age between 35 and 55 & $-.50 * *$ & -5.59 & $-.51 * *$ & -5.63 & .601 \\
\hline Age above 55 & $-.29 * *$ & -3.26 & $-.24 *$ & 2.68 & .788 \\
\hline Financial status A & $-.19 * *$ & 3.78 & $-.19 * *$ & -3.65 & .830 \\
\hline Financial status CD & $.19 * *$ & 3.44 & $.18 * *$ & 3.16 & 1.19 \\
\hline Scotland & .01 & .14 & -.00 & -0.04 & .99 \\
\hline England & -.09 & -1.48 & -.10 & -1.53 & .907 \\
\hline Monthly Payment & $.43^{* *}$ & 7.11 & $.99 * *$ & 13.9 & 2.69 \\
\hline Policy & $.52 * *$ & 3.35 & -.05 & -0.32 & .953 \\
\hline Slope1 & $.07 * *$ & 6.88 & $.08 * *$ & 7.78 & 1.08 \\
\hline
\end{tabular}




\begin{tabular}{|c|c|c|c|c|c|}
\hline Slope2 & $.11 * *$ & 9.21 & $.11 * *$ & 9.63 & 1.12 \\
\hline Slope3 & $-.12 * *$ & -9.35 & $-.13 * *$ & -9.82 & .88 \\
\hline Slope4 & $.23 * *$ & 30.4 & $.23 * *$ & 31.2 & 1.26 \\
\hline Stock Return & $-2.42 * *$ & -8.87 & $-2.32 * *$ & -8.44 & .10 \\
\hline House Price & $-.01 * *$ & -3.24 & $-.01 * *$ & -3.34 & .99 \\
\hline Interest Rate & $-.15^{*}$ & -2.63 & $-.19 * *$ & -3.31 & .83 \\
\hline Confidence Index & .00 & .14 & -.00 & -0.35 & 1.00 \\
\hline Absolute Level & --- & --- & $-.65^{* *}$ & -23.5 & .52 \\
\hline LinearUP & --- & --- & $-1.88^{* *}$ & -18.1 & .15 \\
\hline LinearDW & --- & --- & $-.43 * *$ & -5.20 & .65 \\
\hline QuadUP & --- & --- & -10.53 & -1.29 & .00 \\
\hline QuadDW & --- & --- & $12.95^{*}$ & 2.28 & $\infty$ \\
\hline CubicUP & --- & --- & $-4.6^{*}$ & -2.52 & .01 \\
\hline CubicDW & --- & --- & .11 & .43 & 1.12 \\
\hline Panel II: Heterogeneity \& & on estima & & & & \\
\hline$\sigma_{\varepsilon}^{2}$ & $1.69^{* *}$ & 20.3 & $1.70 * *$ & 21.8 & --- \\
\hline$\sigma_{\delta}^{2}$ & $1.63 * *$ & 7.33 & $1.65 * *$ & 7.41 & --- \\
\hline$\rho_{\varepsilon, \delta}$ & $.29 * *$ & 4.51 & $0.36^{* *}$ & 6.04 & \\
\hline $\begin{array}{l}\text { Log Likelihood with } \\
\text { covariates }\left(L_{m}\right)\end{array}$ & \multicolumn{2}{|c|}{-36687.00} & \multicolumn{3}{|c|}{-36347.78} \\
\hline $\begin{array}{l}\text { Log Likelihood with no } \\
\text { covariates }\left(L_{0}\right)\end{array}$ & \multicolumn{2}{|c|}{-41410.01} & \multicolumn{3}{|c|}{-41410.01} \\
\hline McFadden pseudo $R^{2}$ & \multicolumn{2}{|c|}{0.114} & \multicolumn{3}{|c|}{0.122} \\
\hline
\end{tabular}

Notes: Asterisks * and $* *$ indicate significance at the $5 \%$ and $1 \%$ levels; McFadden pseudo $R^{2}$ is defined as $1-\left(\ln L_{m} / \ln L_{0}\right)$ 
Figure 1: Survival distribution curve function for customer attrition

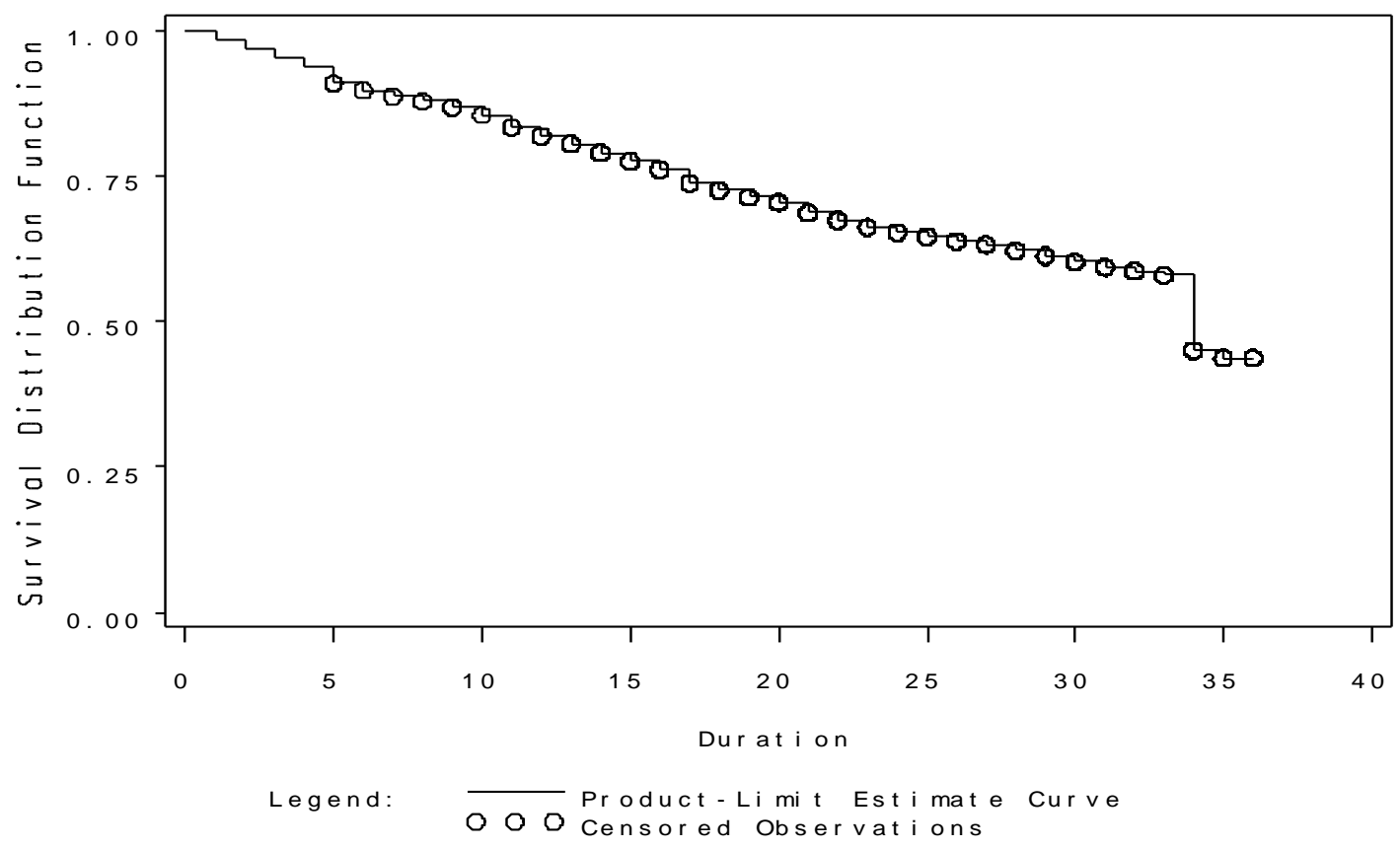

Figure 2: Predictive comparison of ROC using bootstrap

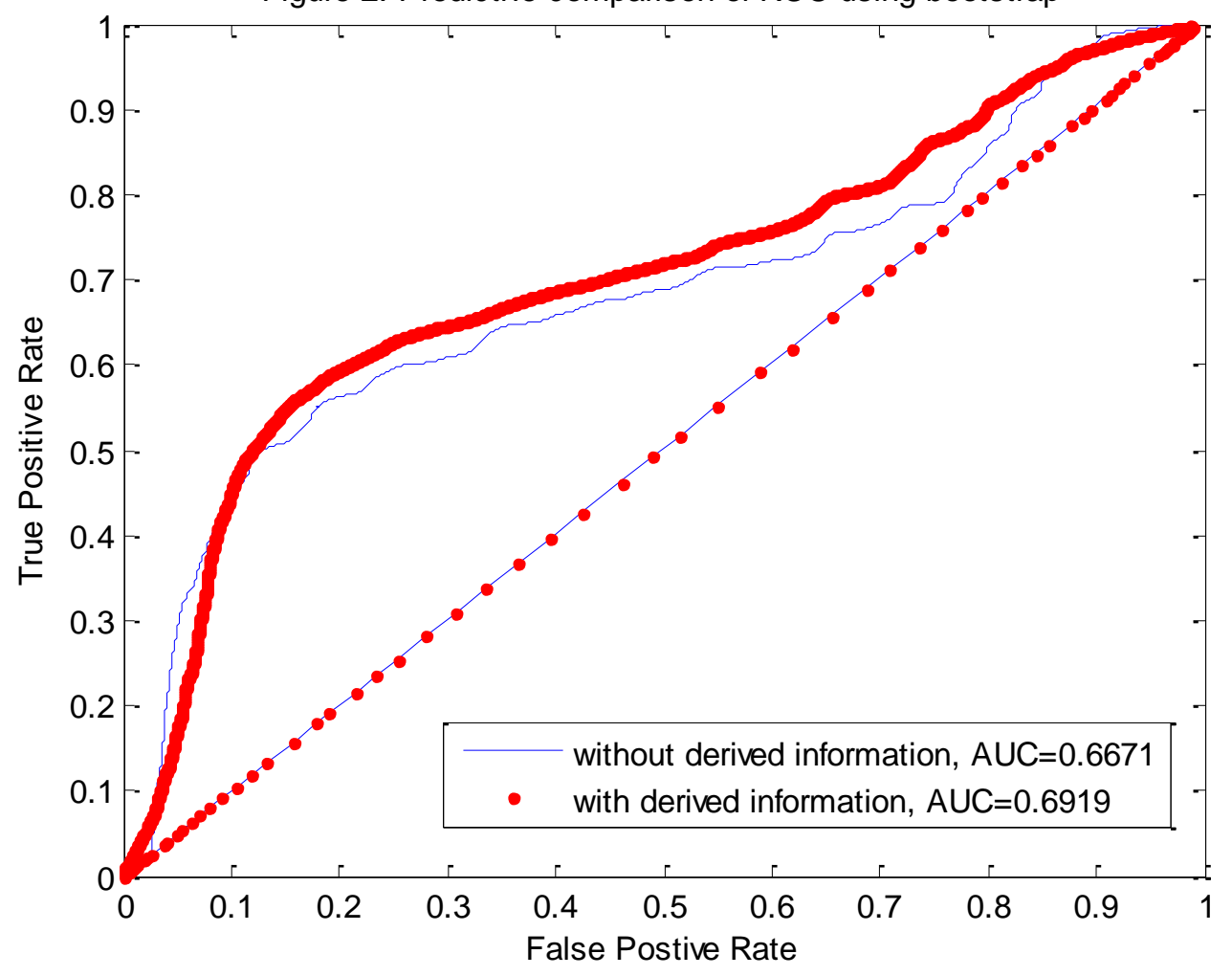


Figure 3: Predictive comparison of ROC using Logistic regression

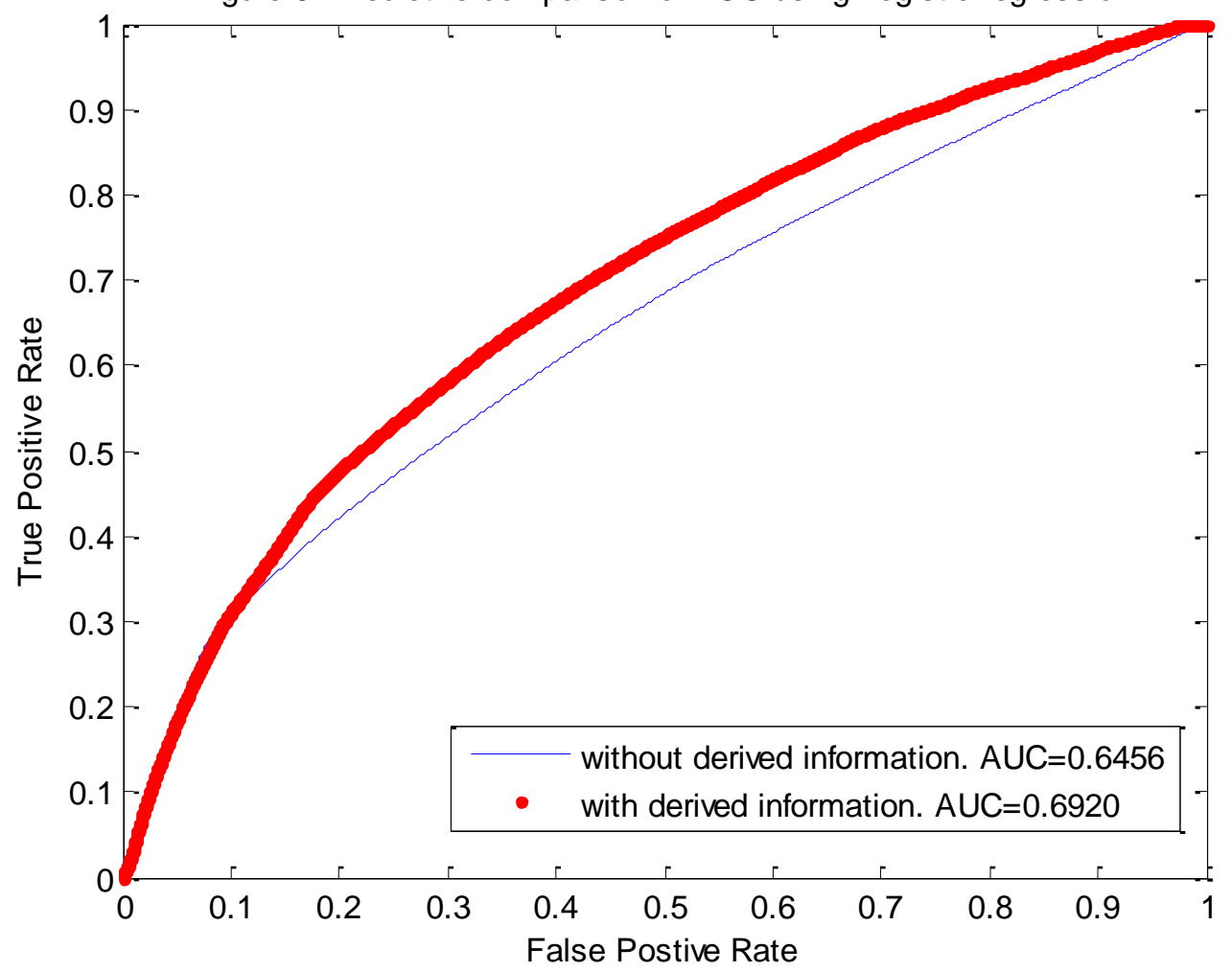

Figure 4: Orthogonal polynomial approximations

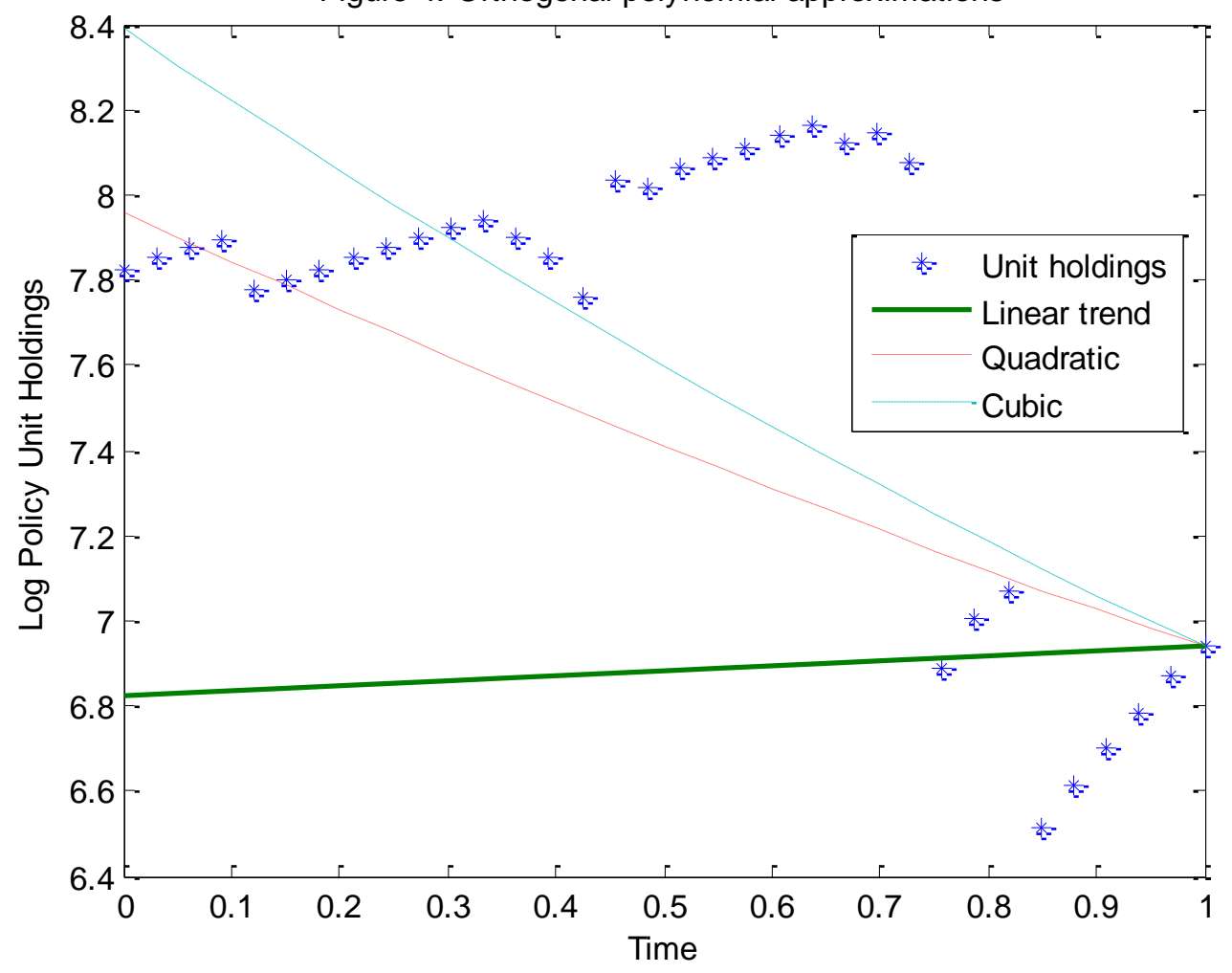

